\title{
Hemangiomas infantis na região da cabeça e pescoço: Papel do Cirurgião-dentista
}

\section{Infantile Hemangiomas in the Head and Neck Region}

Adams DM, Ricci KW. Infantile Hemangiomas in the Head and Neck Region. Otolaryngol Clin North Am. 2018 Feb;51(1):77-87. doi: 10.1016/j.otc.2017.09.009.

Gabriela Lopes dos Santos ${ }^{1}$

O hemangioma infantil $(\mathrm{HI})$ é o tumor benigno vascular mais comumente visto durante a infância. Entretanto suas alterações não são perceptíveis no nascimento, suas características clínicas tornam-se evidentes da $3^{a}$ semana ao $5^{\mathrm{a}}$ mês de vida. Com a evolução clínica do $\mathrm{HI}$ o tecido epitelial do recémnascido sofre alterações de cor e textura. Os HIs são classificados como: superficiais que clinicamente nota-se nas primeiras semanas do nascimento como áreas avermelhadas e com elevação mínima do local afetado. Os HIs profundos são detectados após o $2^{\circ}$ ao $3^{\circ}$ mês de vida, apresentando aumento significativo da área, coloração azulada e temperatura elevada na palpação. Os Hls compostos por sua vez, apresentam elevação e coloração significantemente alteradas, tornando-se fácil seu diagnóstico.

Os Hls além de apresentarem clinicamente diferenças entre si, morfologicamente também expõem distinções importantes para descoberta de possível síndrome subjacente. Esses podem ser lesões solitárias que são as mais comumente vistas, e não necessitam de intervenção caso não apresente complicações ao individuo. As lesões difusas apresentam maiores complicações, como possíveis ulcerações e riscos de lesões nas vias aéreas, e possibilidade de estar associado com alguma síndrome. E lesões múltiplas, essas são inúmeras lesões espalhadas pelo corpo com poucos milímetros de comprimento, geralmente apresentam-se externamente e internamente principalmente no fígado, do individuo.

A maioria dos Hls podem ser diagnosticadas através do exame clínico e história médica pré-existente. Em alguns poucos casos, para fechamento de diagnóstico duvidoso, pedese ultrassonografias, ressonância magnética e biópsia. Embora os HIs não necessitem de intervenções médicas, é importante o profissional da área da saúde apresentar o conhecimento do problema e monitorar o paciente para evitar possíveis complicações ou intervir precocemente.

Hemangiomas que apresentam complicações ou locais anatômicos de alto risco como: periorbital (comprometimento visual), distribuição mandibular (lesões das vias aéreas), área nasal (desfiguração), auricular (ulceração e desfiguração), lombossacral (síndrome LOMBAR), grandes lesões faciais (síndrome PHACE, ulceração, desfiguração) e apresentação multifocal (lesões internas), requerem intervenção medicamentosa. O propranolol, um bloqueador adrenérgico não seletivo, é o tratamento de primeira linha de Hls quando os mesmo apresentam grandes complicações. O propranolol oral é tipicamente iniciado com doses de $1 \mathrm{mg} / \mathrm{kg}$ / d ou menos e alternado para 2 a $3 \mathrm{mg} / \mathrm{kg}$ / d dividido em 2 ou 3 doses. Estudos clínicos

${ }^{1}$ Graduanda de Odontologia - Faculdade de Odontologia de Lins - Universidade Metodista de Piracicaba. 
mostraram complicações minimas quando usado propranalol em bebês e grande eficácia em seu tratamento ${ }^{1}$.

O tratamento para hemangiomas vem envoluindo gradativamente desde 2008, e estudos clínicos de Laranjo e colaboradores em 2014 e estudo imunohistoquimico realizado por Wnek e colaboradores em 2017, comprovam que o uso do propranolol apontam resultados satisfatórios em hemangioma arteriovenoso casos de hemangiomas e pouco ou nenhum efeito colateral significante.

Por que conhecer os hemangiomas infantis ou congênitos? Uma verificação da classificação dos hemangiomas, quer cutâneos ou intrabucais revela que não existe parâmetros completamente claros acerca da natureza destes, ora sendo incluidos como neoplasias benignas, ora como hamartomas, entretanto os hemangiomas são considerados como a neoplasia benigna vascular mais comum. O diagnóstico correto, contudo, é o ponto de partida para um tratamento adequado, principalmente quando há grande aumento de volume, ulceração ou sangramento.Uma atitude inadivertida em um hemangioma arteiovenoso, por exemplo, pode provocar grande hemorragia. Assim também, lesões intra-ósseas requerem um diagnóstico preciso para evitar o mesmo problema. Assim sendo, examesimunohistoquímicos ${ }^{2}$ procuramelucidar a natureza dessas lesões e diferenciando-as de outras como os linfangiomas, granuloma piogênico, que apresentam-se inseridos também nesso contexto. Tratamento frente a diferentes modalidades de tratamento, as escleroses podem ser utilizadas em lesões geralmente menores, porém o propanolol surgiu como promissor nas lesões intrabucais de grande porte.

\section{RefERÊNCIAS BibLIOGRAFICAS}

1- Laranjo S, Costa G, Paramés F, Freitas I, Martins JD, Trigo C, Pinto FF. The role of propranolol in the treatment of infantile hemangioma. Rev Portuguesa de Cardiologia. 2014 May; 33(5): 289-295. doi: https://doi.org/10.1016/j. repc.2013.10.018

2- Wnek A, Andrzejewska E, Kobos J, Taran K, PrzewratilP.Molecularandimmunohistochemical expression of apoptotic proteins $\mathrm{Bax}, \mathrm{Bcl}-2$ and Caspase 3 in infantile hemangioma tissues as an effect of propranolol treatment. Immunology Letters. 2017 May; 185: 27-3. doi: https://doi. org/10.1016/j.imlet.2017.03.005 